\title{
Isoform specificity of protein kinase Cs in synaptic plasticity
}

\author{
Wayne S. Sossin ${ }^{1}$ \\ Department of Neurology and Neurosurgery, Montreal Neurological Institute, McGill University, \\ Montreal, Quebec H3A 2B4, Canada
}

\begin{abstract}
Protein kinase Cs (PKCs) are implicated in many forms of synaptic plasticity. However, the specific isoform(s) of PKC that underlie(s) these events are often not known. We have used Aplysia as a model system in order to investigate the isoform specificity of PKC actions due to the presence of fewer isoforms and a large number of documented physiological roles for PKC in synaptic plasticity in this system. In particular, we have shown that distinct isoforms mediate distinct types of synaptic plasticity induced by the same neurotransmitter: The novel calcium-independent PKC Apl II is required for actions mediated by serotonin (5-HT) alone, while the classical calcium-dependent PKC Apl I is required for actions mediated when 5 - $\mathrm{HT}$ is coupled to activity. We will discuss the reasons for PKC isoform specificity, assess the tools used to uncover isoform specificity, and discuss the implications of isoform specificity for understanding the roles of PKC in regulating synaptic plasticity.
\end{abstract}

\section{Defining PKC isoforms}

\section{There are four major PKC isoforms conserved over evolution}

Much of the difficulty of studying isoform specificity in mammalian PKCs comes from the large number of isoforms (nine genes and at least 11 major isoforms). PKCs are ancient kinases that are present from the time of early animals. To determine the time frame of isoform evolution we performed a Phylip analysis of the kinase domain of PKC isoforms from both mammals and a number of species that mark different evolutionary pathways. We used the kinase domain, since this domain is the most highly conserved, and thus, most useful for detailing evolutionary history. From this analysis it is clear that there are four ancient isoforms of PKC (Fig. 1): a "classical" form with a C2 domain that is sensitive to calcium similar to mammalian PKCs $\alpha, \beta$, and $\gamma$; a "novel" isoform with similarity to mammalian PKCs $\delta$ and $\theta$; a distinct "novel" isoform with similarity to mammalian PKCs $\varepsilon$ and $\eta$; and an atypical isoform with similarity to mammalian PKCs $\zeta$ and $\iota$. These four ancient classes of PKC had already diverged from each other before the bilaterian ancestor, and thus all metazoan animals would be expected to contain at least one of these isoforms, unless an isoform has been lost over evolution. While kinases in yeast have been called PKCs (Levin et al. 1990), due to the presence of a related kinase domain preceded by $\mathrm{C} 1$ and C2 domains, this analysis shows that the kinase domains of these kinases are at least as similar to mammalian PKC-related kinases (PRKs, also known as PKNs), and this is confirmed by the retention in PRKs of a conserved regulatory domain that allows regulation by small GTPases that is also present in yeast "PKCs," but absent in animal PKCs.

Thus, during evolution yeast kinases, PKCs and PKNs diverged from an ancient kinase. Afterward, PKCs diverged into four distinct isoforms. There is a high probability that the atypical PKCs diverged first (Fig. 1); however, the relationship between the other three isoforms is not clear. The analysis shown has the novel form including PKC $\varepsilon$ diverging first, but alternative models for the arrangement of classical and novel PKCs are also sup-

\footnotetext{
${ }^{1}$ Corresponding author.
}

E-mail wayne.sossin@mcgill.ca; fax (514) 398-8106.

Article is online at http://www.learnmem.org/cgi/doi/10.1101//m.469707. ported at lower probabilities (i.e., $\delta$ and $\varepsilon$ families diverging after separation from classical PKCs). During chordate evolution, gene duplications have led to additional closely related isoforms such as PKCs $\alpha, \beta$, and $\gamma$ for the classical PKCs. It is quite surprising that unlike all of the other putative chordate duplications, the kinase domain of $\mathrm{PKC} \varepsilon$ is less similar to $\mathrm{PKC} \eta$ than to invertebrate homologs. While this suggests that $\mathrm{PKC} \eta$ diverged from PKC $\varepsilon$ before the chordate duplication, this seems unlikely since no PKC outside of chordates is more similar to PKC $\eta$ than to PKC $\varepsilon$, and thus one would have to assume that all PKC $\eta$ orthologs had been lost over evolution. More plausible is the possibility that $\mathrm{PKC} \eta$ is diverging at a faster rate than other members of this family. Protein kinase Ds have also been called PKCs $(\mathrm{PKC} \mu)$, but although they contain $\mathrm{C} 1$ domains similar to PKCs and yeast PKCs, the kinase domain is not closely related to the PKC family.

While all PKCs share a common kinase domain and Cterminal extension, they differ in the regulatory region (Fig. 2). Classical PKCs have a pseudosubstrate, followed by tandem C1 domains that bind to diacylglycerol (DAG), and a C2 domain that binds calcium in a phospholipid-dependent manner. Novel PKCs of the $\delta$ and $\varepsilon$ families have an N-terminal C2 domain that does not bind calcium, followed by the pseudosubstrate, and tandem C1 domains that bind to DAG. Finally, atypical PKCs have a PB1 domain involved in protein-protein interactions, followed by the pseudosubstrate and a single atypical C1 domain that does not bind diacylglycerol (DAG).

\section{PKC isoforms in Aplysia}

In this review, we will concentrate on PKC isoform specificity in Aplysia californica, a model system for synaptic plasticity. Initially, two isoforms of PKC were cloned from Aplysia, the classical PKC Apl I and the novel PKC Apl II in the PKC $\varepsilon$ family (Fig. 1) (Kruger et al. 1991). Both fractionation of the nervous system and quantitative immunoprecipitation experiments suggested that these compromised the vast majority of PKCs in the nervous system of this animal (Sossin et al. 1993). These assays used phorbol esters, pharmacological analogs of DAG to identify kinase activity. However, atypical PKCs are not activated by DAG or phorbol esters (Ways et al. 1992; Kazanietz et al. 1993), and would not have been assayed in these experiments. Indeed, we 


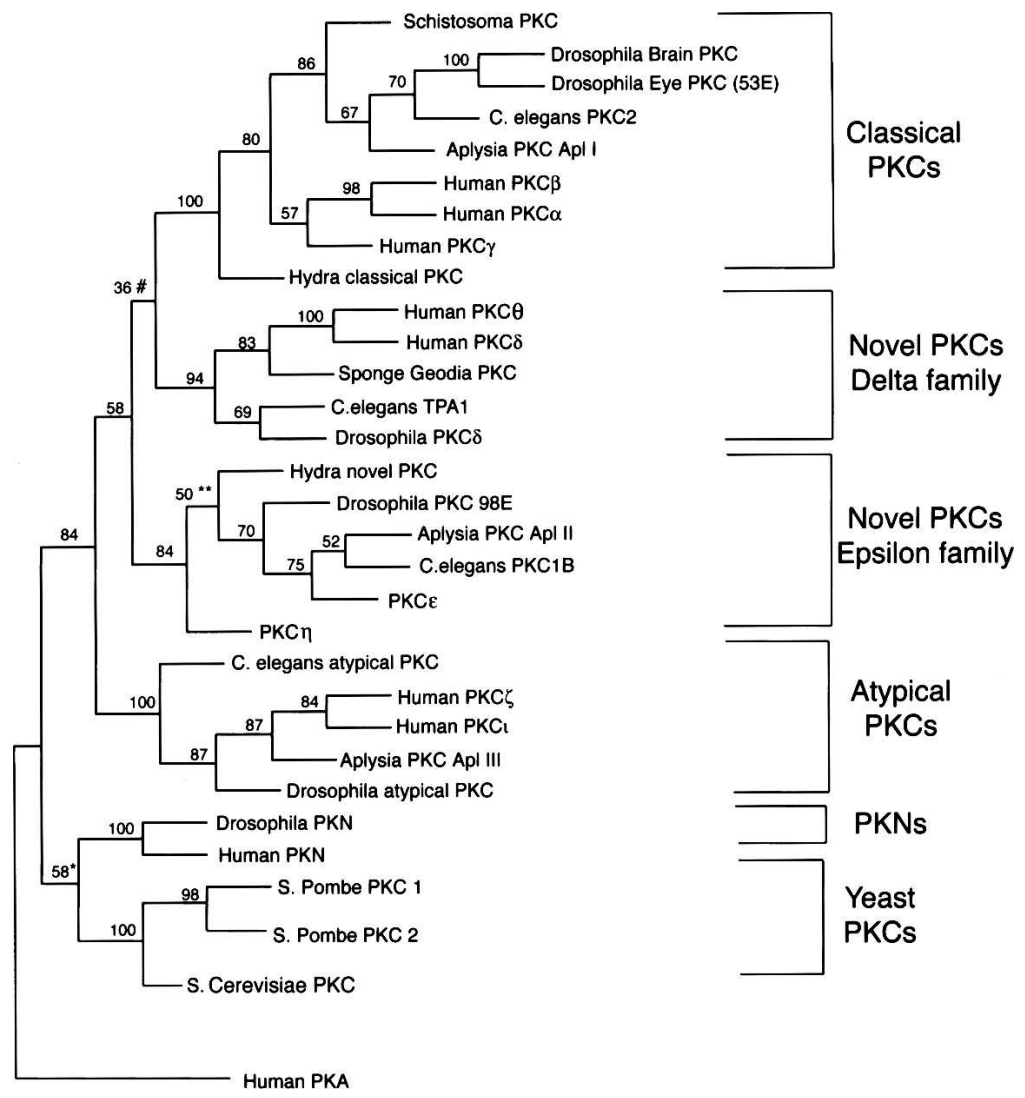

Figure 1. Evolution of kinase domains. Kinase domains were chosen from the public databases using the conserved domain feature of NCBI. Sequences were aligned with Clustal-W, 100 replicates were generated with the Phylip program Seqboot, and then the Phylip program ProtDist was used with the Jones-Taylor-Thornton model to generate a Distance Matrix. Then, the Phylip program Neighbor was used to generate trees from each repetition, the program Consense used to generate the consensus tree, and Drawgram used to make the final tree shown. Bootstrap numbers are given in each node and represent the percentage of total trees that gave the tree shown. For more information on these programs, please see $\mathrm{http}: / /$ evolution.genetics.washington.edu/phylip/phylipweb.html. $\left.{ }^{*}{ }^{*}\right)$ This low bootstrap number is due to an alternative tree with PKN, Yeast PKCs, and PKCs all as separate groups with a bootstrap of 42. (\#) This low bootstrap value is due to the presence of alternative trees for the order of separation of the classes.

have recently isolated an atypical PKC from Aplysia that we have named PKC Apl III, which is expressed in the nervous system (Bougie et al. 2006). From the above analysis, it also seems likely that the genome of Aplysia would contain a novel isoform with similarity to PKCס. Using the trace archives of the Aplysia genome publicly available on the NIH Web site (http://www. ncbi.nlm.nih.gov/blast/mmtrace.shtml), there is clearly a PKC $\delta$ like kinase domain in the genome of Aplysia; however, this isoform was not detected in the Aplysia nervous system EST collection (Moroz et al. 2006). Moreover, it seems unlikely that it is a major isoform in the nervous system (Sossin et al. 1993) and instead may be expressed in other tissues like muscle, which contain little PKC Apl I or PKC Apl II (Kruger et al. 1991), but considerable phorbol-ester-activated PKC activity (W. Sossin, unpubl.).

\section{What determines the isoform specificity of PKC?}

There are a number of reasons that a particular isoform of PKC could be linked to a specific type of physiological event such as synaptic plasticity. Different isoforms are expressed in distinct neurons or distinct subcellular regions of a neuron (e.g., postsynaptic density). There are differences in the requirements of different isoforms to be activated (Fig. 3). For example, classical
PKCs require calcium for activity, while novel and atypical PKCs do not, and thus different isoforms may be activated by distinct stimuli. Finally, isoform specificity can be due to differences in substrate specificity between the isoforms, either due to intrinsic differences in the substrate-binding pocket, or because of differences in protein-protein interactions required to localize the kinase in close proximity to the substrate (Fig. 4). We will discuss each of these possibilities below, first describing results from Aplysia and their generality for mammalian PKCs.

\section{Anatomical and subcellular localizations of PKCs}

In Aplysia, PKC Apl I and PKC Apl II appear to be present in most neurons and in most compartments; thus, this is not a major reason for isoform specificity between these isoforms (Kruger et al. 1991). The atypical PKC Apl III also appears to be distributed fairly ubiquitously (Bougie et al. 2006). In contrast, there appears to be little PKC $\delta$-like activity in the nervous system (Sossin et al. 1993). Similarly, in mammals, while there are some differences in the relative neuronal distribution of the different isoforms, in general, most isoforms are found in many different kinds of neurons and in both presynaptic and postsynaptic compartments (Minami et al. 2000; Naik et al. 2000). Similar to Aplysia, the novel $\delta$ family, PKCs $\delta$ and $\theta$, are expressed at low levels in most neurons, although there are subpopulations of neurons where these kinases are highly expressed, such as PKC $\delta$ in the thalamus (Minami et al. 2000; Naik et al. 2000).

\section{Differential activation of PKC isoforms}

Even when multiple isoforms are present in a subcellular compartment, they may not all be activated during plasticity. In Aplysia sensory neurons, this is one major cause for isoform specificity: PKC Apl II is activated by 5-HT alone, while PKC Apl I is not (Zhao et al. 2006). We will discuss reasons for this differential activation below.

\section{Activation by lipid}

PKCs all have a pseudosubstrate in the regulatory domain that binds to the catalytic domain, keeping the enzyme in a closed inactive state. PKCs are then activated by a conformational change in the regulatory domain that occurs upon lipid binding, which removes the pseudosubstrate from the catalytic domain, allowing substrates to be phosphorylated (Newton 1995b). For classical and novel PKCs, lipid binding is greatly enhanced by DAG binding to the $\mathrm{C} 1$ domains. A major determinant of isoform specificity between classical and novel PKCs is the C2 domain. Classical PKCs have a C2 domain that binds lipids in a calciumdependent manner (Newton 1995a). Lipid binding by the C2 domain of classical PKCs has two functions: first, it helps localize PKC to the membrane (Newton 1995a; Oancea and Meyer 1998; Cho 2001); second, it removes an inhibitory effect of the C2 


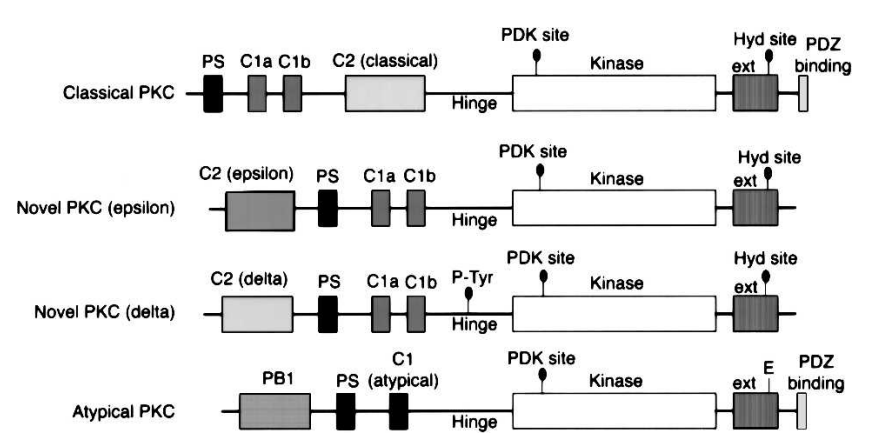

Figure 2. Structure of PKC isoforms. One typical structure for each class of PKC isoform is shown. (PS) Pseudosubstrate; (ext) C-terminal extension; (Hyd site) hydrophobic site; (E) glutamic acid replacing hydrophobic site in atypical PKCs; (PDK) phosphoinositide-dependent kinase 1; (P-Tyr) tyrosine phosphate. The C 2 domains of the novel PKCs $\delta$ and $\varepsilon$ are shaded differently to emphasize the difference in these domains. Similarly, the C1 domain of atypical PKCs is shaded distinctly, as it does not have the conserved residues required for DAG binding. The PDZ site shown in classical PKCs is not present in all isoforms, but is present in eye-specific PKC in Drosophila, Aplysia PKC Apl I, and PKC $\alpha$ in vertebrates.

domain on DAG binding to the $\mathrm{C} 1$ domain (Medkova and Cho 1999; Cho 2001; Slater et al. 2002). Classical PKCs, like PKC Apl $\mathrm{I}$, thus require calcium in association with DAG for translocation to membranes and activation (Zhao et al. 2006) (Fig. 3). Similarly, imaging of PKC $\gamma$ in hippocampal neurons showed that a conjunction of DAG production downstream of phospholipase $\mathrm{C}$ (PLC) activation and calcium was required for translocation (Codazzi et al. 2006). One difference between classical isoforms in vertebrates is in the affinity of their $\mathrm{C} 2$ domains for calcium in vitro, with PKC $\gamma$ being the most sensitive $(0.7 \mu \mathrm{M})$ and PKC $\beta$ the least $(5 \mu \mathrm{M})$ (Torrecillas et al. 2004). It is not clear how this relates to the calcium concentrations required for translocation in cells, since the level of calcium required will change with different concentrations of lipid and DAG. It will be interesting in the future to combine live imaging of PKC translocation with calcium imaging to determine how much calcium is required for translocation and whether this differs between the classical isoforms.

If classical PKCs require calcium-dependent lipid binding to the C2 domain for translocation, do novel PKCs require their C2 domain for translocation as well? The C2 domain of novel PKCs is located N-terminal to the pseudosubstrate and lacks residues for calcium binding (Fig. 2). The C2 domain of PKC Apl II and vertebrate PKC $\varepsilon$ binds lipid poorly or not at all (Pepio et al. 1998; Corbalan-Garcia et al. 2003; Cho and Stahelin 2006), although in Aplysia, this binding is increased after phosphorylation (Pepio and Sossin 2001). Removing the C2 domain in PKC Apl II enhances PKC activation and translocation, suggesting that the major role of this domain is inhibitory (Pepio et al. 1998; C. AbiFarah and W. Sossin, unpubl.). Similarly, in vertebrate PKCs, removing the C2 domain of novel PKCs either facilitates translocation or has no effect (Stahelin et al. 2005; Giorgione et al. 2006). There is some evidence that facilitated translocation of novel PKCs is due to a higher membrane affinity of their C1 domains for DAG (Giorgione et al. 2006; Dries et al. 2007), although in vitro assays measuring the affinity of the novel C1 domains for DAG do not reveal significantly higher affinities for DAG than classical C1 domains (Corbalan-Garcia and GomezFernandez 2006). In Aplysia, PKC Apl II is translocated to membranes by 5 -HT alone. This is probably due both to a higher affinity for DAG and additional second messengers such as phosphatidic acid that can synergize with DAG to activate PKC Apl II (Pepio and Sossin 1998; Pepio et al. 1998; Zhao et al. 2006; C. Abi-Farah and W. Sossin, unpubl.). Phosphatidic acid has also been shown to be required for translocation of PKC $\varepsilon$ (Jose LopezAndreo et al. 2003) (Fig. 4).

PKC $\delta$ and $\theta$ have a $\mathrm{C} 2$ domain in the same position as the PKC $\varepsilon$ family, but the two C2 domains are highly divergent and differ in structure (Pappa et al. 1998; Ochoa et al. 2001). The $\delta$-like PKC C2 domains do no bind lipid, but instead bind phosphotyrosine and are involved in activation of the kinase through protein-protein interactions (Benes et al. 2005).

Neither DAG nor calcium activates the atypical PKCs, but lipid binding to the $\mathrm{C} 1$ domain is still important for activation. Atypical PKCs have a PB1 domain N-terminal to the pseudosubstrate and protein-protein interactions through this domain are important for activation (Moscat and Diaz-Meco 2000; Henrique and Schweisguth 2003; Hirano et al. 2004).

\section{Activation by phosphorylation}

PKCs are also regulated by phosphorylation (Keranen et al. 1995) (Fig. 2). All isoforms require phosphorylation by the enzyme phospho-inositide-dependent kinase (PDK) for activity (Chou et al. 1998; Dutil et al. 1998; Le Good et al. 1998; Balendran et al. 2000). For most classical and novel PKCs, this phosphorylation occurs initially after translation of the kinase, and in its absence the kinase does not fold into a conformation that allows for phosphate transfer and is quickly degraded (Balendran et al. 2000). In contrast, atypical PKCs do not need this site for stability, and in these kinases, phosphorylation of this site is highly regulated in a PIP-3-dependent fashion and is a mechanism for controling kinase activity (Chou et al. 1998; Balendran et al. 2000) (Fig. 3). Classical and novel PKCs are also phosphorylated at a hydrophobic site in a C-terminal extension that is a glutamic acid in atypical PKCs (Fig. 2) (Newton 1995b; Parekh et al. 1999). Phosphorylation of this site stabilizes the enzyme and increases the specific activity of PKCs, including PKC Apl II (Bornancin and Parker 1997; Edwards and Newton 1997; Lim and Sossin 2006). While PKCs can autophosphorylate this site in vitro (Keranen et al. 1995; Behn-Krappa and Newton 1999; Cenni et al. 2002), expression of PKCs with mutations that remove their kinase activity are still phosphorylated at this site (Rybin et al. 2003; Lim and Sossin 2006), suggesting additional mechanisms other than autophosphorylation. The TOR/Rictor complex (rapamycin-insensitive TOR) has been implicated in phosphorylation of this site in cells (Sarbassov et al. 2004). Phosphorylation of PKC Apl II at this site (and the PDK-site) is increased during persistent activation of the kinase (Pepio et al. 2002; Lim and Sossin 2006), and thus, may play a regulatory role layered on top of lipid regulation. There have been a number of publications where increased phosphorylation of this site has been used as a marker of PKC activation (Zhou et al. 2003; Birnbaum et al. 2004; Sivasankaran et al. 2004), but whether phosphorylation at this site is a cause or effect of PKC activation is not clear at present.

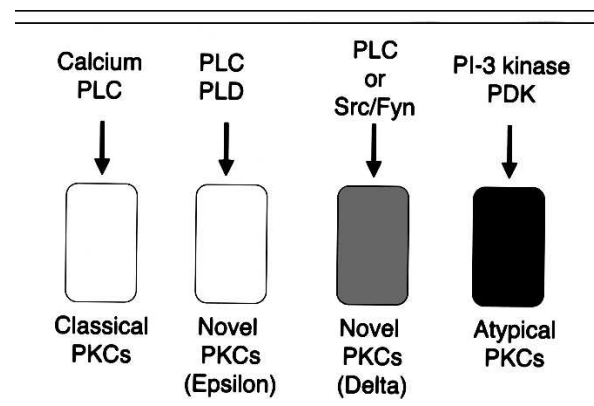

Figure 3. Differential Activation of $P K C$ isoforms. The major activators of the distinct classes of PKC are shown. (PLC) Phospholipase C; (PLD) Phospholipase D. 


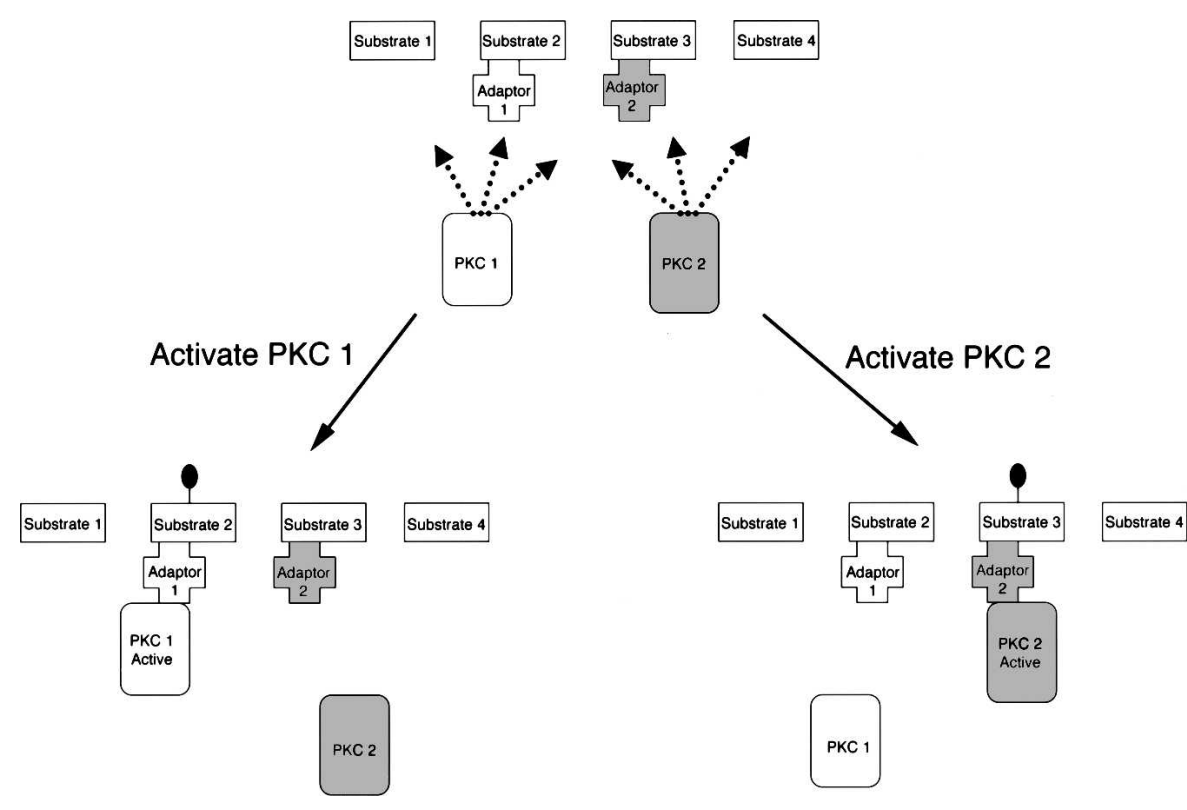

Figure 4. Substrate specificity of PKC isoforms. The different reasons for substrate specificity are illustrated in this figure for two hypothetical PKC isoforms, 1 and 2, and four substrates. Dashed arrows between PKC and substrates indicate that the PKC site in these substrates could be phosphorylated by this isoform and is an illustration of intrinsic substrate specificity. Thus, the site in substrate 1 can only be phosphorylated by PKC 1 , the site in substrate 4 can only be phosphorylated by PKC 2 , while the sites in substrates 2 and 3 can be phosphorylated by both isoforms. The adaptor proteins can link PKC activation to a specific substrate. Thus, when PKC 1 is activated it will preferentially phosphorylate substrate 2 (dark phosphorylation circle) because of the presence of a specific adaptor protein to link the kinase to this substrate (Adaptor 1). In contrast, activation of PKC 2 will preferentially phosphorylate substrate 3 because of the presence of a distinct adaptor (Adaptor 2).

PKC $\delta$ is activated by tyrosine phosphorylation in the hinge domain (Konishi et al. 2001; Kikkawa et al. 2002). This activation appears to be independent of cleavage or production of DAG (Kikkawa et al. 2002). PKC $\delta$ is also phosphorylated in the C2 domain on a tyrosine residue (Li et al. 1996), and this site appears to be important for some functions of PKC $\delta$, but not for PKC $\delta$ activity (Kronfeld et al. 2000; Kikkawa et al. 2002). Phosphorylation of PKC $\delta$ on tyrosines is facilitated by binding of activated tyrosine kinases (such as Src and Fyn) by the phosphotyrosinebinding C2 domain of PKC $\delta$ (Benes et al. 2005). This mechanism appears to be specific to this class of PKCs (Fig. 3).

\section{Activation by cleavage}

PKCs can be activated by cleavage in the hinge domain to form an enzyme known as a PKM. This form of the kinase is autonomous (does not require lipids or DAG), since it lacks the pseudosubstrate from the regulatory domain. PKC $\delta$ is cleaved by caspases after apoptotic stimuli and PKM $\delta$ contributes to the apoptosis response (Kikkawa et al. 2002; Brodie and Blumberg 2003). There is evidence that PKMs may contribute to persistent activation of PKCs during memory formation in many systems including Aplysia (see below) (Grunbaum and Muller 1998; Sutton et al. 2004). In vertebrates, a PKM form of the atypical PKC $\zeta$, $\mathrm{PKM} \zeta$ plays an important role in synaptic plasticity and memory in vertebrates (Pastalkova et al. 2006) (see below). However, in this case the PKM is not formed by cleavage, but instead a distinct mRNA that encodes $\mathrm{PKM} \zeta$ is formed from an alternative transcriptional start site generated by a promoter found in an intron

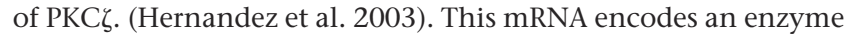
that lacks the pseudosubstrate domain, and is thus constitutively active.

\section{Activation by oxidation}

PKC may also be activated by oxidation (Knapp and Klann 2000). This is probably due to oxidation of cysteines in the C1 domain causing a conformational change similar to lipid binding (Knapp and Klann 2000). Superoxides can be formed during synaptic plasticity and superoxide-dependent activation of PKC has been shown to be important for LTP in vertebrates (Knapp and Klann 2002). In Aplysia, PKC Apl I was preferentially activated by oxidation, but there was no evidence for a physiological role of superoxide in PKC activation by 5 -HT in Aplysia (Zabouri and Sossin 2002).

\section{Measurement of kinase activation}

There are multiple ways to measure PKC activation. Measuring kinase activity in vitro by immunoprecipitation of the kinase from cell lysates and then measuring the ability of the isolated kinase to phosphorylate substrates can detect changes in kinase activity due to phosphorylation or other post-translational modifications. While this is a common way to measure kinases other than PKC, since lipid-dependent conformational changes are the major mechanism for PKC activation, this type of assay is not of particular use for determining whether PKC is activated by a specific stimulation. Instead, activation of PKC can be measured by its translocation to the membrane fraction, a measurement of lipid activation (Sando 2003). This can be determined using subcellular fractionation after lysing cells; however, this technique has several problems, especially in the nervous system. First, the biochemical fraction contains a mixture of different neuronal types where activation of PKCs may be distinct. Second, it is difficult to retain the cellular conditions required for translocation after lysing the cells (Sando 2003). Imaging translocation of fluorescently tagged PKCs is advantageous, since it allows for examination of translocation in individual intact cells (Saito 2003). However, one needs to be cautious of perturbations due to overexpression of the kinase and the possibility that the tag can affect translocation (Saito 2003). Finally, PKC activity is sometimes measured by its phosphorylation state. However, as described above, the role of phosphorylation in the activation of the kinase is still debatable, and in most cases, phosphorylation is not sufficient for activation, and thus not a reliable marker for kinase activation.

Our examination of PKCs in Aplysia offers a cautionary tale for examining isoform specificity using subcellular fractionation. Initial studies used subcellular fractionation from a substantial part of the nervous system. These experiments suggested translocation of the classical calcium-dependent PKC Apl I, but not the novel $\varepsilon$-like PKC Apl II by 5-HT (Sossin and Schwartz 1992). However, examination by imaging of GFP-tagged PKCs in sensory neurons showed the opposite result, 5-HT translocated PKC Apl II, but not PKC Apl I in sensory neurons (Zhao et al. 2006). The results with GFP-tagged PKCs are consistent with physiological results using dominant-negative PKCs (Manseau et al. 2001; Zhao et al. 2006) (see below). In retrospect, the earlier results can be explained by two problems. The nondetection of PKC Apl II translocation was due to the limited number of cells in which 
PKC Apl II is translocated; for example, the more numerous and larger motor neurons do not show 5-HT-mediated PKC translocation (Zhao et al. 2006). The false detection of PKC Apl I was probably due to an inability to control cellular calcium levels, either during dissection of the ganglia or after lysis, since it is clear from live imaging studies that PKC Apl I requires calcium for translocation (Zhao et al. 2006), but in intact cells 5-HT does not increase intracellular calcium levels (Blumenfeld et al. 1990).

\section{Substrate specificity of PKC isoforms}

Even when multiple PKCs are activated by the same stimulus, there can still be isoform specificity in their physiological roles through their phosphorylation of distinct substrates. This specificity can be driven by intrinsic differences in the catalytic site or due to protein-protein interactions of PKC that localize activated PKC close to particular substrates (Fig. 4).

\section{Intrinsic substrate specificity of PKCs}

There is little evidence for intrinsic substrate specificity within a class of PKCs, but there are differences in optimum substrates between classes (Nishikawa et al. 1997; Fujii et al. 2004). Classical PKCs prefer basic residues $\mathrm{N}$-terminal $(\mathrm{P}+2, \mathrm{P}+3)$ to the substrate, while most novel PKCs prefer hydrophobic residues (Nishikawa et al. 1997). PKC $\zeta$ poorly phosphorylates peptides with a hydrophobic residue in the $\mathrm{P}-1$ position, while PKC $\delta$ phosphorylation is not affected by this residue (Fujii et al. 2004). In contrast, PKC $\delta$ poorly phosphorylates peptides with a hydrophobic site in the $\mathrm{P}-2$ position, while $\mathrm{PKC} \zeta$ phosphorylation is not affected by this residue (Fujii et al. 2004). Thus, certain residues near the phosphorylation site may determine the class of PKC that can phosphorylate a particular substrate sequence. However, other sites can still be phosphorylated by all PKCs (Fig. 4).

\section{Specificity due to protein-protein interactions}

Many protein kinases are localized to their substrates independently of the specificity of the substrate-binding pocket. There have been a number of protein-protein interactions that have been shown to be important for isoform specificity of PKCs. These interactions occur in the C2 domain, the PB1 domain for atypical PKCs, and through C-terminal interactions with PDZ proteins.

\section{RACK}

The receptors for activated $\mathrm{C}$ kinase (RACKs) bind to activated PKCs to localize PKC function to specific substrates (Schechtman and Mochly-Rosen 2001). Initially, RACK1 was proposed to bind to the C2 domain of classical PKCs (Ron et al. 1995), but additional specificity for PKC $\beta I I$ was due to additional interactions in the C-terminal extension (Stebbins and Mochly-Rosen 2001), and interactions between novel PKCs and RACK have also been described (Besson et al. 2002). RACK has been shown to be important for PKC phosphorylation of GABA receptors and the apoptotic kinase Jnk (Brandon et al. 2002; Lopez-Bergami et al. 2005), although RACK has not been shown to be isoform specific for these phosphorylations. RACK is localized in a number of cellular regions, but is most abundant on ribosomes, and may be particularly important in PKC regulation of translation (Nilsson et al. 2004).

\section{PKC and the cytoskeleton}

PKC regulates the cytoskeleton and this involves both direct interactions both between PKC and the cytoskeleton and between PKC and cytoskeleton-associated proteins (Larsson 2006). In Aplysia, both PKC Apl I and PKC Apl II bind to actin filaments and microtubule bundles and are translocated to the cytoskeleton by phorbol esters (Nakhost et al. 1998, 2002; Kabir et al.
2001). In contrast, 5-HT translocates PKCs to the plasma membrane, and not to the cytoskeleton (Zhao et al. 2006). The physiological stimulus that causes PKC translocation to the cytoskeleton is not clear, but even in the absence of stimuli, PKC Apl I and PKC Apl II are associated with the cytoskeleton in growth cones (Nakhost et al. 1998, 2002). In some cases the cytoskeleton can replace phospholipids for the activation of PKCs (Blobe et al. 1996) or retain PKC in an active conformation (Prekeris et al. 1996). In vertebrates, isoform-specific regions have been shown to enhance PKC associations with actin for both $\mathrm{PKC} \varepsilon$ (Prekeris et al. 1996) and PKCßII (Blobe et al. 1996; Slater et al. 2000). The interaction of PKC $\varepsilon$ with actin is important for the ability of PKC $\varepsilon$ to increase glutamate release in synaptosomes (Prekeris et al. 1996). This sequence is not conserved in PKC Apl II, but a neighboring region that has also been implicated in $\mathrm{PKC} \varepsilon$ cytoskeleton interactions is conserved (Ling et al. 2005).

\section{PDZ-binding sites}

Some PKCs have C-terminal residues that allow for binding to proteins containing PDZ domains. The prototypical example of this is the eye-specific classical PKC in Drosophila that binds to the phototransduction-signaling scaffold INAD (Adamski et al. 1998). Binding is required for PKC's role in visual adaptation in this system (Adamski et al. 1998). PKC Apl I contains a PDZbinding region, and this site may localize Apl I near its targets for regulating transmitter release (Wan et al. 2006). In vertebrates, PKC $\alpha$ contains a PDZ-binding site that binds to PICK (Staudinger et al. 1997), and this is important for plasticity (see below). This is a major difference between classical isoforms in vertebrates, since PKC $\beta 1, \beta I I$, and $\gamma$ all lack this site. Atypical PKCs contain a highly conserved PDZ-binding site, although there has been little work at defining its role and binding partners.

\section{PB1-binding proteins}

Atypical PKCs have been shown to bind many proteins through the PB1 domain at its N-terminal (Moscat and Diaz-Meco 2000). This includes PAR- 6 that directs atypical PKCs to regulate cell polarity (Ohno 2001) and ZIP proteins that couple atypical PKCs to regulation of ion channels (Gong et al. 1999). None of these interactions are important for $\mathrm{PKM} \zeta$, since it does not contain the regulatory PB1 domain. However, PKM $\zeta$ does still retain the PDZbinding domain, and it will be interesting to determine whether this is important for its substrate specificity.

\section{Isoform-specific inhibitors}

To determine the role of specific isoforms in plasticity, one requires isoform-specific inhibitors. These include pseudosubstrate-based peptides, inhibitors based on the ATP-binding site, peptides based on the RACK binding sites, dominant-negative kinases, and genetic or siRNA-based removal of specific isoforms.

\section{Pseudosubstrate-based peptides}

Peptides based on the pseudosubstrate sequence, the region of the regulatory domain that naturally occupies the substratebinding pocket in the inactivated kinase, are commonly used as PKC inhibitors. However, since all PKCs phosphorylate similar sequences, these peptides are not necessarily isoform specific. In Aplysia, pseudosubstrate-based peptides from PKC Apl I and PKC Apl II were not isoform-specific inhibitors (Sossin and Schwartz 1992). While pseudosubstrate-based peptides based on the classical PKCs (PKC19-31 or PKC19-36) are commonly used to block PKC activity, it does not distinguish between novel and classical PKCs, and probably also inhibits other kinases such as CAMKII (Hvalby et al. 1994). In contrast, the myristoylated ZIP peptide based on the pseudosubstrate of the atypical PKC $\zeta$ has been used

\section{Learning \& Memory}


as a specific inhibitor of atypical PKCs (Liu et al. 2000; Ling et al. 2002).

\section{Inhibitors based on ATP-binding site}

Staurosoporine was initially identified as a PKC inhibitor that was a competitive inhibitor for ATP (Tamaoki et al. 1986). While staurosporine has been shown to inhibit many related kinases, derivatives of staurosporine have been developed as PKC-specific and isoform-specific inhibitors that are widely used. Bisindoylmaleamide I/GF 109203x is an effective and fairly specific inhibitor of most classical and novel PKCs, but is largely inactive against atypical PKCs (Toullec et al. 1991), including Apl III (T. Lim and W. Sossin, unpubl.). Several derivatives of staurosporine (Gö 6976, $\mathrm{R}_{0}$-32-0432), are selective for classical PKCs compared with novel PKCs in vertebrates (Martiny-Baron et al. 1993; Mizuno et al. 1993), although they do not distinguish between PKC Apl I and PKC Apl II in Aplysia (W. Sossin, unpubl.). These inhibitors can even distinguish between classical isoforms; LY333531 can specifically inhibit PKC $\beta$ as opposed to PKC $\alpha$ or $\gamma$ (Ishii et al. 1996).

\section{Other pharmacological inhibitors}

Chelerythrine binds to the substrate-binding pocket and appears to inhibit all classes of PKC (Herbert et al. 1990), but may be more specific for PKMs (Ling et al. 2002; T. Lim and W. Sossin, unpubl.) due to greater access to the substrate-binding pocket in the absence of the pseudosubstrate. Calphostin- $\mathrm{C}$ inhibits the kinase by binding to the $\mathrm{C} 1$ domain and then inactivating the enzyme irreversibly through free radical production and destruction of the kinase (Gopalakrishna et al. 1992). Atypical PKCs and PKMs are thus not inhibited by calphostin C.

\section{Peptides based on RACK binding}

Since RACK binds only to activated PKC, the RACK-binding site is presumed to be hidden in the inactive kinase by a pseudoRACK site. Inhibitor peptides based on the RACK-binding site can block kinase activity either by blocking RACK binding or by interacting with the pseudo-RACK site, keeping the enzyme in an inactive conformation (Schechtman and Mochly-Rosen 2001). Peptides based on the pseudo-RACK site are also used as isoformspecific PKC activators (Schechtman and Mochly-Rosen 2001). Many of these peptides are based on sequences in the C2 domain, and they may also affect PKCs by causing conformational changes in the enzyme irrespective of their effect on blocking PKC binding to interacting partners (Schechtman et al. 2004).

\section{Dominant-negative PKCs}

Expression of kinase-dead PKCs (PKCs where the kinase domain has been mutated so that it cannot transfer ATP) can act as dominant-negatives by competing with endogenous PKCs for proteinprotein interactions or substrate binding (Toker 2003). Since protein-protein interactions are often isoform specific, these can be isoform-specific inhibitors. At high levels, the kinase-dead PKCs may become nonspecific by competing for shared PKC requirements such as DAG and the activating enzyme PDK (GarciaParamio et al. 1998). In Aplysia, dominant-negative PKC Apl I and dominant-negative PKC Apl II appear to be isoform specific, since they inhibit distinct forms of synaptic plasticity (Zhao et al. 2006). There are also numerous examples of dominant-negative PKCs demonstrating isoform specificity in other systems (Soh et al. 1999; Sivasankaran et al. 2004).

\section{Knockouts, antisense, and siRNAs}

Removing specific isoforms of PKCs, through antisense oligonucleotides or siRNAs, can remove individual PKC isoforms and thus be used to determine isoform specificity (Irie et al. 2002; Toker 2003). The stability of PKC is an issue for antisense and siRNA techniques, since they do not remove previously synthe- sized enzyme, and this may be an issue in the nervous system. In mice, the usefulness of knockouts can be limited by the redundancy of PKCs within a class; however, there are some interesting isoform-specific effects of PKC knockouts on synaptic plasticity (see below).

\section{Roles for PKC in synaptic plasticity}

\section{Roles for PKC in Aplysia}

Most research in Aplysia has focused on the plasticity between sensory and motor neurons that underlies behavioral sensitization (Kandel 2001). Release of 5-HT from interneurons is necessary and sufficient for behavioral sensitization (Glanzman et al. 1989; Byrne et al. 1993). 5-HT-mediated increases in the strength of the synapse between the sensory and motor neurons, called facilitation, is a cellular analog of sensitization (Byrne et al. 1993; Byrne and Kandel 1996). PKC activity is required for several aspects of facilitation, including facilitation at synapses that have been previously depressed (Ghirardi et al. 1992), prolonged facilitation when 5-HT is coupled to activity (Sutton and Carew 2000), and facilitation after longer applications of 5-HT (Byrne and Kandel 1996; Hawkins et al. 2006). PKC has also been linked to a number of secondary physiological effects of 5-HT in sensory neurons, including the modifications of ion channels (Sawada et al. 1989; Critz and Byrne 1992; Sugita et al. 1992; Braha et al. 1993; Byrne and Kandel 1996) and the regulation of protein synthesis (Yanow et al. 1998).

\section{PKC Apl II is critical for the reversal of synaptic depression induced by $5-H T$}

The sensory-motor neuron synapse shows significant depression even when stimulated at low frequencies, and this is linked to behavioral habituation (Castellucci et al. 1970; Castellucci and Kandel 1974). This synaptic depression can be reversed by application of 5-HT, and this is linked to behavioral dishabituation (Hochner et al. 1986b; Hawkins et al. 2006). Interestingly, the mechanism for the reversal of synaptic depression is distinct from that of the facilitation of nondepressed synapses, as the reversal of depression is dependent on PKC, while facilitation of nondepressed synapses at early times is dependent on PKA (Ghirardi et al. 1992). The reversal of depression is mediated by PKC Apl II. 5-HT application is sufficient to translocate PKC Apl II, but not PKC Apl I (Zhao et al. 2006) and dominant-negative PKC Apl II, but not dominant-negative PKC Apl I blocks 5-HT mediated reversal of depression (Manseau et al. 2001). Thus, PKC Apl II can phosphorylate a protein important for the reversal of depression, although this substrate is still not known. The specific proteinprotein interactions required for this form of synaptic plasticity are not clear, but the fact that the PKC Apl II C2 domain alone did not act as a dominant negative suggests that any interaction was not mediated through the C2 domain (Manseau et al. 2001).

The actions of PKC Apl II are likely to regulate some aspect of the release process. Interestingly, the vertebrate homolog of PKC Apl II, PKC $\varepsilon$, has also been strongly implicated in the regulation of transmitter release in vertebrate neurons (Terrian et al. 1991; Prekeris et al. 1996; Saitoh et al. 2001) and the Caenorhabditis elegans ortholog (PKC-1) has also been recently implicated in regulating transmitter release (Sieburth et al. 2007). There may be highly conserved substrates and/or highly conserved proteinprotein interactions that underlie this role.

\section{Why does PKC Apl II not cause facilitation of} nondepressed synapses after short applications of 5-HT? Despite the fact that 5-HT translocates PKC Apl II during facilitation as well, neither inhibitors of PKC nor dominant-negative 
PKC Apl II blocks synaptic facilitation measured at 5 min after 5-HT application in nondepressed synapses (Ghirardi et al. 1992; Manseau et al. 2001). This suggests that PKC Apl II cannot phosphorylate proteins involved in facilitation at this time point. In contrast, activation of PKC with PDBu can facilitate nondepressed synapses (Braha et al. 1990; Houeland et al. 2007). This is not due to a non-PKC effect of phorbol esters, since PKC inhibitors block facilitation by PDBu (Braha et al. 1990; Houeland et al. 2007). Thus, since both PKC Apl I and PKC Apl II are activated by PDBu (Zhao et al. 2006), it suggests that PKC Apl I can phosphorylate a protein that causes facilitation of nondepressed synapses, and the reason 5-HT does not cause facilitation through PKC is due to the lack of translocation of PKC Apl I. The substrate involved in PDBu facilitation is probably SNAP-25, since expression of SNAP-25 with the PKC site mutated to alanine blocks PDBu-mediated facilitation (Houeland et al. 2007). PKC phosphorylation of SNAP-25 has also been shown to be important in regulating transmitter release in vertebrates, although the isoform of PKC involved has not been determined (Nagy et al. 2002).

\section{Does PKC Apl II cause facilitation at later times through increasing spike broadening?}

Longer applications of 5-HT can cause facilitation that is more sensitive to PKC inhibitors (Byrne and Kandel 1996; Hawkins et al. 2006). While spike broadening is sufficient to increase transmitter release (Hochner et al. 1986a; Klein 1994), at early time points 5-HT causes facilitation largely independently of increases in spike broadening (Klein 1994). However, spike broadening increases with longer applications of 5-HT, and this later increase is sensitive to PKC inhibitors and is probably due to PKC regulation of a voltage-dependent potassium channel (Baxter and Byrne 1989; Sugita et al. 1992; 1994). Prolonged applications of 5-HT do not activate PKC Apl I (Y. Zhao, K. Martin, M. Klein, and W. Sossin, unpubl.), so this is also probably due to activation of PKC Apl II. However, it is not clear why this effect is delayed compared with the reversal of depression. It is not due to delayed activation of PKC Apl II, but could be due to requirements for additional steps downstream of PKC activation for this modulation (i.e., insertion of channels), or due to poor efficiency of PKC phosphorylation of this substrate.

\section{PKC Apl I is critical for the induction}

\section{of intermediate facilitation}

When 5-HT is coupled with synaptic activity, a form of intermediate-term facilitation (ITF) is induced that lasts for hours after stimulation (Bailey et al. 2000; Sutton and Carew 2000). Interestingly, PKC is important both for the induction and the expression of ITF (Sutton and Carew 2000). While PKC Apl I is not translocated by $5-\mathrm{HT}$ alone, it is translocated when the sensory neuron is fired in the presence of 5-HT (Zhao et al. 2006). Furthermore, dominant-negative forms of PKC Apl I block ITF, but dominant-negative forms of PKC Apl II do not (Zhao et al. 2006). In this case, isoform specificity is not due to selectivity of activation, since PKC Apl II is also activated during ITF, but suggests that PKC Apl I can phosphorylate specific proteins not accessible to PKC Apl II, perhaps SNAP-25.

The requirement for both activation of a G-protein-coupled receptor leading to PLC activation and DAG production and calcium entry through voltage-gated channels seen for PKC Apl I is also seen in other models of synaptic plasticity. In Purkinje neurons, the combination of mGLUR1 receptor activation and depolarization induces long-term depression (LTD) of parallel fiberPurkinje synapses that is important for behavioral plasticity, such as eye-blink conditioning (Linden 2003). The requirement for the conjunction of DAG and calcium suggests a requirement for a classical isoform of PKC; indeed, cerebellar LTD is not present in PKC $\alpha$ knockout mice (Leitges et al. 2004). Interestingly, the association of PKC $\alpha$ with its PDZ partner PICK is also important for this plasticity (Leitges et al. 2004), presumably PICK binding localizes PKC $\alpha$ to the glutamate receptor subunit, GluR2, since PKC phosphorylation of GluR2 is required for LTD (Chung et al. 2003). This requirement explains the isoform specificity for PKC $\alpha$, since expressing PKC $\gamma$ with the PKC $\alpha$ PDZ-binding domain can rescue LTD in cultured Purkinje neurons lacking PKC $\alpha$ (Leitges et al. 2004).

It is somewhat surprising that in the nervous system, activation of classical PKCs is rarely seen with just PLC activation, since PLC also produces inositol triphosphate (IP3) that should release calcium from internal stores. In contrast, as seen above, activation of classical PKCs, at least in the nervous system, requires additional calcium inputs. This may be due to dissociation of IP3 production from IP3 receptors in the absence of linking proteins like Homer (Tu et al. 1998) or the requirements for fairly high levels of calcium for PKC activation in cells. In Aplysia, 5HT does not cause release of internal calcium from sensory neurons despite the ability of injected IP3 to do so (Blumenfeld et al. 1990), suggesting that there is a dissociation of IP3 production and activation of IP3 receptors.

\section{Additional isoform-specific effects in vertebrates revealed by $\mathrm{KO}$ mice}

All isoforms of PKC (with the exception of PKM $\zeta$ ) have been knocked out in mice, and a number have been examined for effects on various types of synaptic plasticity. As mentioned above, PKC $\alpha$ plays a role in cerebellar LTD and associated motor tasks. PKC $\beta$ knockout mice have a deficit in fear conditioning, perhaps due to its abundance in the cellular locus for this memory, the amygdyla (Weeber et al. 2000). PKC $\gamma$ knockout mice have some deficits in LTP and LTD, and a number of other specific deficits in regulation of $G$ protein-coupled receptors (Saito and Shirai 2002). The limited effects of classical PKC KOs suggest that there is probably redundancy in the roles of these closely related kinases. There have been no reported effects of changes in synaptic plasticity in PKC $\delta$ KO mice, but outside the nervous system there are major effects on apoptosis (Humphries et al. 2006), and it is likely that this will also be true in the nervous system. Removal of PKC $\varepsilon$ has revealed major roles in sensory neurons relevant to pain sensation (Khasar et al. 1999; Aley et al. 2000), the response to ethanol (Dina et al. 2000; Olive et al. 2001), and ischemic preconditioning (Raval et al. 2003). PKC $\theta$ has been implicated in activity-dependent synapse elimination at the neuromuscular junction (Li et al. 2004).

\section{PKMs are important for persistent forms of synaptic plasticity and memory}

In Aplysia, the persistence of activity-dependent ITF and of sitespecific sensitization depends on persistent activation of PKC for expression, since PKC inhibitors also block the expression of ITF (Sutton and Carew 2000; Sutton et al. 2004). This is probably due to the formation of a PKM form of PKC, since calphostin-C cannot block the expression of ITF, suggesting that the persistently active PKC has lost its regulatory domain (Sutton et al. 2004). Furthermore, inhibitors of the protease calpain block activation of ITF, consistent with a need to form a PKM for ITF (Sutton et al. 2004). In the honeybee, intermediate memories are also linked to formation of a PKM (Grunbaum and Muller 1998). Both the persistence of LTP and of behavioral memory in vertebrates have also been linked to the formation of a PKM; but in this case, it is not due to proteolysis of a classical PKC, but instead to the translation of $\mathrm{PKM} \zeta$, which is formed using an alternative transcrip-

\section{Learning \& Memory}


tional start site (see above; Hernandez et al. 2003). Remarkably, inhibiting $\mathrm{PKM} \zeta$ with a pseudosubstrate-based inhibitor can reverse both previously established LTP and memories in the hippocampus, suggesting that continuous PKM $\zeta$ activation is required for the persistence of some memories (Ling et al. 2002; Serrano et al. 2005; Pastalkova et al. 2006). Whether the substrates phosphorylated by $\mathrm{PKM} \zeta$ are isoform specific or the isoform specificity is due to the unique activation of PKM $\zeta$ at this time is not known, as the substrate(s) important for the role of $\mathrm{PKM} \zeta$ have not been identified. It has also been reported that PKM $\zeta$ can be formed in Drosophila, although it is not clear whether or not this is due to proteolysis or a unique transcriptional initiation site similar to vertebrates (Drier et al. 2002). There is no evidence so far for a PKM Apl III in Aplysia formed from an alternative transcription start in the PKC Apl III gene (G. Ferraro, T. Lim, and W. Sossin, unpubl.).

\section{Summary}

We have reviewed the isoform specificity of PKCs in synaptic plasticity. Different isoforms play distinct roles for many reasons, including differential activation and differential targeting through isoform-specific protein-protein interactions. In general, novel PKCs probably are more easily activated by PLC activation and may play important roles in activity-independent forms of plasticity, while classical isoforms are designed to detect the conjunction of activity and G protein-coupled receptor activation. Persistent forms of synaptic plasticity sometimes rely on autonomous forms of PKC, notably PKMs.

\section{Acknowledgments}

This work was supported by CIHR grant MT-12046. W.S. is supported by an FRSQ Chercheurs nationaux and is a William Dawson Scholar. I thank Vincent Castellucci for helpful comments and collaborations and Carole Abi-Farah for helpful suggestions.

\section{References}

Adamski, F.M., Zhu, M.Y., Bahiraei, F., and Shieh, B.H. 1998. Interaction of eye protein kinase C and INAD in Drosophila. Localization of binding domains and electrophysiological characterization of a loss of association in transgenic flies. J. Biol. Chem. 273: 17713-17719.

Aley, K.O., Messing, R.O., Mochly-Rosen, D., and Levine, J.D. 2000. Chronic hypersensitivity for inflammatory nociceptor sensitization mediated by the $\varepsilon$ isozyme of protein kinase C. J. Neurosci. 20: $4680-4685$.

Bailey, C.H., Giustetto, M., Zhu, H., Chen, M., and Kandel, E.R. 2000. A novel function for serotonin-mediated short-term facilitation in Aplysia: Conversion of a transient, cell-wide homosynaptic hebbian plasticity into a persistent, protein synthesis-independent synapse-specific enhancement. Proc. Natl. Acad. Sci. 97: 11581-11586.

Baxter, D.A. and Byrne, J.H. 1989. Serotonergic modulation of two potassium currents in the pleural sensory neurons of Aplysia. J. Neurophysiol. 62: 665-679.

Balendran, A., Hare, G.R., Kieloch, A., Williams, M.R., and Alessi, D.R. 2000. Further evidence that 3-phosphoinositide-dependent protein kinase-1 (PDK1) is required for the stability and phosphorylation of protein kinase C (PKC) isoforms. FEBS Lett. 484: 217-223.

Behn-Krappa, A. and Newton, A.C. 1999. The hydrophobic phosphorylation motif of conventional protein kinase $\mathrm{C}$ is regulated by autophosphorylation. Curr. Biol. 9: 728-737.

Benes, C.H., Wu, N., Elia, A.E., Dharia, T., Cantley, L.C., and Soltoff, S.P. 2005. The C2 domain of PKC $\delta$ is a phosphotyrosine binding domain. Cell 121: 271-280.

Besson, A., Wilson, T.L., and Yong, V.W. 2002. The anchoring protein RACK1 links protein kinase $\mathrm{C} \varepsilon$ to integrin $\beta$ chains. Requirements for adhesion and motility. J. Biol. Chem. 277: 22073-22084.

Birnbaum, S.G., Yuan, P.X., Wang, M., Vijayraghavan, S., Bloom, A.K., Davis, D.J., Gobeske, K.T., Sweatt, J.D., Manji, H.K., and Arnsten, A.F. 2004. Protein kinase C overactivity impairs prefrontal cortical regulation of working memory. Science 306: 882-884.

Blobe, G.C., Stribling, D.S., Fabbro, D., Stabel, S., and Hannun, Y.A. 1996. Protein kinase C $\beta$ II specifically binds to and is activated by
F-actin. J. Biol. Chem. 271: 15823-15830.

Blumenfeld, H., Spira, M.E., Kandel, E.R., and Siegelbaum, S.A. 1990. Facilitatory and inhibitory transmitters modulate calcium influx during action potentials in Aplysia sensory neurons. Neuron 5: $487-499$.

Bornancin, F. and Parker, P.J. 1997. Phosphorylation of protein kinase C- $\alpha$ on serine 657 controls the accumulation of active enzyme and contributes to its phosphatase-resistant state. J. Biol. Chem. 272: 3544-3549.

Bougie, J., Lim, T., Ferraro, G., Manjunath, V., Scott, D., and Sossin, W.S. 2006. Cloning and characterization of protein kinase C (PKC) Apl III, a homologue of atypical PKCs in Aplysia. Soc. Neurosci. Abstract 669.610.

Braha, O., Dale, N., Hochner, B., Klein, M., Abrams, T.W., and Kandel, E.R. 1990. Second messengers involved in the two processes of presynaptic facilitation that contribute to sensitization and dishabituation in Aplysia sensory neurons. Proc. Natl. Acad. Sci. 87: 2040-2044

Braha, O., Edmonds, B., Sacktor, T., Kandel, E.R., and Klein, M. 1993. The contributions of protein kinase $\mathrm{A}$ and protein kinase $\mathrm{C}$ to the actions of 5-HT on the L-type $\mathrm{Ca}^{2+}$ current of the sensory neurons in Aplysia. J. Neurosci. 13: 1839-1851.

Brandon, N.J., Jovanovic, J.N., Smart, T.G., and Moss, S.J. 2002. Receptor for activated C kinase-1 facilitates protein kinase C-dependent phosphorylation and functional modulation of GABA(A) receptors with the activation of G-protein-coupled receptors. J. Neurosci. 22: 6353-6361.

Brodie, C. and Blumberg, P.M. 2003. Regulation of cell apoptosis by protein kinase c $\delta$. Apoptosis 8: 19-27.

Byrne, J.H. and Kandel, E.R. 1996. Presynaptic facilitation revisited: State and time dependence. J. Neurosci. 16: 425-435.

Byrne, J.H., Zwartjes, R., Homayouni, R., Critz, S.D., and Eskin, A. 1993. Roles of second messenger pathways in neuronal plasticity and in learning and memory. Insights gained from Aplysia. Adv. Second Messenger Phosphoprotein Res. 27: 47-108.

Castellucci, V.F. and Kandel, E.R. 1974. A quantal analysis of the synaptic depression underlying habituation of the gill-withdrawal reflex in Aplysia. Proc. Natl. Acad. Sci. 71: 5004-5008.

Castellucci, V., Pinsker, H., Kupfermann, I., and Kandel, E.R. 1970. Neuronal mechanisms of habituation and dishabituation of the gill-withdrawal reflex in Aplysia. Science 167: 1745-1748.

Cenni, V., Doppler, H., Sonnenburg, E.D., Maraldi, N., Newton, A.C., and Toker, A. 2002. Regulation of novel protein kinase $\mathrm{C} \varepsilon$ by phosphorylation. Biochem. J. 363: 537-545.

Cho, W. 2001. Membrane targeting by C1 and C2 domains. J. Biol. Chem. 276: 32407-32410.

Cho, W. and Stahelin, R.V. 2006. Membrane binding and subcellular targeting of C2 domains. Biochim. Biophys. Acta 1761: 838-849.

Chou, M.M., Hou, W.M., Johnson, J., Graham, L.K., Lee, M.H., Chen, C.S., Newton, A.C., Schaffhausen, B.S., and Toker, A. 1998. Regulation of protein kinase $\mathrm{C} \zeta$ by PI 3-kinase and PDK-1. Curr. Biol. 8: 1069-1077.

Chung, H.J., Steinberg, J.P., Huganir, R.L., and Linden, D.J. 2003. Requirement of AMPA receptor GluR2 phosphorylation for cerebellar long-term depression. Science 300: 1751-1755.

Codazzi, F., Di Cesare, A., Chiulli, N., Albanese, A., Meyer, T., Zacchetti, D., and Grohovaz, F. 2006. Synergistic control of protein kinase C activity by ionotropic and metabotropic glutamate receptor inputs in hippocampal neurons. J. Neurosci. 26: 3404-3411.

Corbalan-Garcia, S. and Gomez-Fernandez, J.C. 2006. Protein kinase C regulatory domains: The art of decoding many different signals in membranes. Biochim. Biophys. Acta 1761: 633-654.

Corbalan-Garcia, S., Sanchez-Carrillo, S., Garcia-Garcia, J., and Gomez-Fernandez, J.C. 2003. Characterization of the membrane binding mode of the $\mathrm{C} 2$ domain of PKC $\varepsilon$. Biochemistry 42: $11661-11668$.

Critz, S.D. and Byrne, J.H. 1992. Modulation of IK,Ca by phorbol ester-mediated activation of PKC in pleural sensory neurons of Aplysia. J. Neurophysiol. 68: 1079-1086.

Dina, O.A., Barletta, J., Chen, X., Mutero, A., Martin, A., Messing, R.O., and Levine, J.D. 2000. Key role for the $\varepsilon$ isoform of protein kinase C in painful alcoholic neuropathy in the rat. J. Neurosci. 20: $8614-8619$.

Drier, E.A., Tello, M.K., Cowan, M., Wu, P., Blace, N., Sacktor, T.C., and Yin, J.C. 2002. Memory enhancement and formation by atypical PKM activity in Drosophila melanogaster. Nat. Neurosci. 5: 316-324

Dries, D.R., Gallegos, L.L., and Newton, A.C. 2007. A single residue in the $\mathrm{C} 1$ domain sensitizes novel protein kinase $\mathrm{C}$ isoforms to cellular diacylglycerol production. J. Biol. Chem. 282: 826-830.

Dutil, E.M., Toker, A., and Newton, A.C. 1998. Regulation of conventional protein kinase $\mathrm{C}$ isozymes by phosphoinositide-dependent kinase 1 (PDK-1). Curr. Biol. 
8: $1366-1375$.

Edwards, A.S. and Newton, A.C. 1997. Phosphorylation at conserved carboxyl-terminal hydrophobic motif regulates the catalytic and regulatory domains of protein kinase C. J. Biol. Chem. 272: 18382-18390.

Fujii, K., Zhu, G., Liu, Y., Hallam, J., Chen, L., Herrero, J., and Shaw, S. 2004. Kinase peptide specificity: Improved determination and relevance to protein phosphorylation. Proc. Natl. Acad. Sci. 101: 13744-13749.

Garcia-Paramio, P., Cabrerizo, Y., Bornancin, F., and Parker, P.J. 1998. The broad specificity of dominant inhibitory protein kinase $C$ mutants infers a common step in phosphorylation. Biochem. J. 333: 631-636.

Ghirardi, M., Braha, O., Hochner, B., Montarolo, P.G., Kandel, E.R., and Dale, N. 1992. Roles of PKA and PKC in facilitation of evoked and spontaneous transmitter release at depressed and nondepressed synapses in Aplysia sensory neurons. Neuron 9: 479-489.

Giorgione, J.R., Lin, J.H., McCammon, J.A., and Newton, A.C. 2006. Increased membrane affinity of the $\mathrm{C} 1$ domain of protein kinase $\mathrm{C} \delta$ compensates for the lack of involvement of its C2 domain in membrane recruitment. J. Biol. Chem. 281: 1660-1669.

Glanzman, D.L., Mackey, S.L., Hawkins, R.D., Dyke, A.M., Lloyd, P.E., and Kandel, E.R. 1989. Depletion of serotonin in the nervous system of Aplysia reduces the behavioral enhancement of gill withdrawal as well as the heterosynaptic facilitation produced by tail shock. $J$. Neurosci. 9: 4200-4213.

Gong, J., Xu, J., Bezanilla, M., van Huizen, R., Derin, R., and Li, M. 1999. Differential stimulation of PKC phosphorylation of potassium channels by ZIP1 and ZIP2. Science 285: 1565-1569.

Gopalakrishna, R., Chen, Z.H., and Gundimeda, U. 1992. Irreversible oxidative inactivation of protein kinase $\mathrm{C}$ by photosensitive inhibitor calphostin C. FEBS Lett. 314: 149-154.

Grunbaum, L. and Muller, U. 1998. Induction of a specific olfactory memory leads to a long-lasting activation of protein kinase $\mathrm{C}$ in the antennal lobe of the honeybee. J. Neurosci. 18: 4384-4392.

Hawkins, R.D., Kandel, E.R., and Bailey, C.H. 2006. Molecular mechanisms of memory storage in Aplysia. Biol. Bull. 210: 174-191.

Henrique, D. and Schweisguth, F. 2003. Cell polarity: The ups and downs of the Par6/aPKC complex. Curr. Opin. Genet. Dev. 13: $341-350$.

Herbert, J.M., Augereau, J.M., Gleye, J., and Maffrand, J.P. 1990. Chelerythrine is a potent and specific inhibitor of protein kinase C. Biochem. Biophys. Res. Commun. 172: 993-999.

Hernandez, A.I., Blace, N., Crary, J.F., Serrano, P.A., Leitges, M., Libien, J.M., Weinstein, G., Tcherapanov, A., and Sacktor, T.C. 2003. Protein kinase $M \zeta$ synthesis from a brain mRNA encoding an independent protein kinase $\mathrm{C} \zeta$ catalytic domain. Implications for the molecular mechanism of memory. J. Biol. Chem. 278: 40305-40316.

Hirano, Y., Yoshinaga, S., Ogura, K., Yokochi, M., Noda, Y., Sumimoto, H., and Inagaki, F. 2004. Solution structure of atypical protein kinase C PB1 domain and its mode of interaction with ZIP/p62 and MEK5. J. Biol. Chem. 279: 31883-31890.

Hochner, B., Klein, M., Schacher, S., and Kandel, E.R. 1986a. Action-potential duration and the modulation of transmitter release from the sensory neurons of Aplysia in presynaptic facilitation and behavioral sensitization. Proc. Natl. Acad. Sci. 83: 8410-8414.

Hochner, B., Klein, M., Schacher, S., and Kandel, E.R. 1986b. Additional component in the cellular mechanism of presynaptic facilitation contributes to behavioral dishabituation in Aplysia. Proc. Natl. Acad. Sci. 83: 8794-8798.

Houeland, G., Nakhost, A., Sossin, W.S., and Castellucci, V.F. 2007. PKC modulation of transmitter release by SNAP-25 at sensory to motor synapses in Aplysia. J. Neurophysiol. 97: 134-143.

Humphries, M.J., Limesand, K.H., Schneider, J.C., Nakayama, K.I., Anderson, S.M., and Reyland, M.E. 2006. Suppression of apoptosis in the protein kinase C $\delta$ null mouse in vivo. J. Biol. Chem. 281: 9728-9737.

Hvalby, O., Hemmings Jr., H.C., Paulsen, O., Czernik, A.J., Nairn, A.C., Godfraind, J.M., Jensen, V., Raastad, M., Storm, J.F., Andersen, P., et al. 1994. Specificity of protein kinase inhibitor peptides and induction of long-term potentiation. Proc. Natl. Acad. Sci. 91: 4761-4765.

Irie, N., Sakai, N., Ueyama, T., Kajimoto, T., Shirai, Y., and Saito, N. 2002. Subtype- and species-specific knockdown of PKC using short interfering RNA. Biochem. Biophys. Res. Commun. 298: 738-743.

Ishii, H., Jirousek, M.R., Koya, D., Takagi, C., Xia, P., Clermont, A., Bursell, S.E., Kern, T.S., Ballas, L.M., Heath, W.F., et al. 1996. Amelioration of vascular dysfunctions in diabetic rats by an oral PKC $\beta$ inhibitor. Science 272: 728-731.

Jose Lopez-Andreo, M., Gomez-Fernandez, J.C., and Corbalan-Garcia, S 2003. The simultaneous production of phosphatidic acid and diacylglycerol is essential for the translocation of protein kinase $C \varepsilon$ to the plasma membrane in RBL-2H3 cells. Mol. Biol. Cell 14: $4885-4895$.

Kabir, N., Schaefer, A.W., Nakhost, A., Sossin, W.S., and Forscher, P. 2001. Protein kinase $\mathrm{C}$ activation promotes microtubule advance in neuronal growth cones by increasing average microtubule growth lifetimes. J. Cell Biol. 152: 1033-1044.

Kandel, E.R. 2001. The molecular biology of memory storage: A dialogue between genes and synapses. Science 294: 1030-1038.

Kazanietz, M.G., Areces, L.B., Bahador, A., Mischak, H., Goodnight, J., Mushinski, J.F., and Blumberg, P.M. 1993. Characterization of ligand and substrate specificity for the calcium-dependent and calcium-independent protein kinase C isozymes. Mol. Pharmacol. 44: $298-307$.

Keranen, L.M., Dutil, E.M., and Newton, A.C. 1995. Protein kinase C is regulated in vivo by three functionally distinct phosphorylations. Curr. Biol. 5: 1394-1403.

Khasar, S.G., Lin, Y.H., Martin, A., Dadgar, J., McMahon, T., Wang, D., Hundle, B., Aley, K.O., Isenberg, W., McCarter, G., et al. 1999. A novel nociceptor signaling pathway revealed in protein kinase $\mathrm{C} \varepsilon$ mutant mice. Neuron 24: 253-260.

Kikkawa, U., Matsuzaki, H., and Yamamoto, T. 2002. Protein kinase C $\delta$ (PKC 8): Activation mechanisms and functions. J. Biochem. 132: 831-839

Klein, M. 1994. Synaptic augmentation by 5-HT at rested Aplysia sensorimotor synapses: Independence of action potential prolongation. Neuron 13: 159-166.

Knapp, L.T. and Klann, E. 2000. Superoxide-induced stimulation of protein kinase $\mathrm{C}$ via thiol modification and modulation of zinc content. J. Biol. Chem. 275: 24136-24145.

Knapp, L.T. and Klann, E. 2002. Potentiation of hippocampal synaptic transmission by superoxide requires the oxidative activation of protein kinase C. J. Neurosci. 22: 674-683.

Konishi, H., Yamauchi, E., Taniguchi, H., Yamamoto, T., Matsuzaki, H., Takemura, Y., Ohmae, K., Kikkawa, U., and Nishizuka, Y. 2001. Phosphorylation sites of protein kinase $\mathrm{C} \delta$ in $\mathrm{H}_{2} \mathrm{O}_{2}$-treated cells and its activation by tyrosine kinase in vitro. Proc. Natl. Acad. Sci. 98: 6587-6592.

Kronfeld, I., Kazimirsky, G., Lorenzo, P.S., Garfield, S.H., Blumberg, P.M., and Brodie, C. 2000. Phosphorylation of protein kinase C $\delta$ on distinct tyrosine residues regulates specific cellular functions. J. Biol. Chem. 275: 35491-35498.

Kruger, K.E., Sossin, W.S., Sacktor, T.C., Bergold, P.J., Beushausen, S., and Schwartz, J.H. 1991. Cloning and characterization of $\mathrm{Ca}^{2+}$-dependent and $\mathrm{Ca}^{2+}$-independent PKCs expressed in Aplysia sensory cells. J. Neurosci. 11: 2303-2313.

Larsson, C. 2006. Protein kinase C and the regulation of the actin cytoskeleton. Cell. Signal. 18: 276-284.

Le Good, J.A., Ziegler, W.H., Parekh, D.B., Alessi, D.R., Cohen, P., and Parker, P.J. 1998. Protein kinase C isotypes controlled by phosphoinositide 3-kinase through the protein kinase PDK1. Science 281: 2042-2045.

Leitges, M., Kovac, J., Plomann, M., and Linden, D.J. 2004. A unique PDZ ligand in PKC $\alpha$ confers induction of cerebellar long-term synaptic depression. Neuron 44: 585-594.

Levin, D.E., Fields, F.O., Kunisawa, R., Bishop, J.M., and Thorner, J. 1990. A candidate protein kinase C gene, PKC1, is required for the $S$. cerevisiae cell cycle. Cell 62: 213-224.

Li, W., Chen, X.H., Kelley, C.A., Alimandi, M., Zhang, J., Chen, Q., Bottaro, D.P., and Pierce, J.H. 1996. Identification of tyrosine 187 as a protein kinase C- $\delta$ phosphorylation site. J. Biol. Chem. 271: 26404-26409.

Li, M.X., Jia, M., Yang, L.X., Jiang, H., Lanuza, M.A., Gonzalez, C.M., and Nelson, P.G. 2004. The role of the $\theta$ isoform of protein kinase C (PKC) in activity-dependent synapse elimination: Evidence from the PKC $\theta$ knock-out mouse in vivo and in vitro. J. Neurosci. 24: 3762-3769.

Lim, T. and Sossin, W.S. 2006. Phosphorylation at the hydrophobic site of protein kinase C Apl II is increased during intermediate term facilitation. Neuroscience 141: 277-285.

Linden, D.J. 2003. Neuroscience. From molecules to memory in the cerebellum. Science 301: 1682-1685.

Ling, D.S., Benardo, L.S., Serrano, P.A., Blace, N., Kelly, M.T., Crary, J.F., and Sacktor, T.C. 2002. Protein kinase $\mathrm{M} \zeta$ is necessary and sufficient for LTP maintenance. Nat. Neurosci. 5: 295-296.

Ling, M., Troller, U., Zeidman, R., Stensman, H., Schultz, A., and Larsson, C. 2005. Identification of conserved amino acids N-terminal of the PKC $\varepsilon$ C1b domain crucial for protein kinase $C \varepsilon$-mediated induction of neurite outgrowth. J. Biol. Chem. 280: 17910-17919.

Liu, K., Hsiung, S., Adlersberg, M., Sacktor, T., Gershon, M.D., and Tamir, H. 2000. $\mathrm{Ca}^{2+}$-evoked serotonin secretion by parafollicular cells: Roles in signal transduction of phosphatidylinositol 3'-kinase, and the $\gamma$ and $\zeta$ isoforms of protein kinase C. J. Neurosci. 
20: $1365-1373$.

Lopez-Bergami, P., Habelhah, H., Bhoumik, A., Zhang, W., Wang, L.H., and Ronai, Z. 2005. RACK1 mediates activation of JNK by protein kinase C. Mol. Cell 19: 309-320.

Manseau, F., Fan, X., Hueftlein, T., Sossin, W., and Castellucci, V.F. 2001. $\mathrm{Ca}^{2+}$-independent PKC Apl II mediates the serotonin induced facilitation at depressed synapses in Aplysia. J. Neurosci. 21: $1247-1256$.

Martiny-Baron, G., Kazanietz, M.G., Mischak, H., Blumberg, P.M., Kochs, G., Hug, H., Marme, D., and Schachtele, C. 1993. Selective inhibition of protein kinase $\mathrm{C}$ isozymes by the indolocarbazole Gö 6976. J. Biol. Chem. 268: 9194-9197.

Medkova, M. and Cho, W. 1999. Interplay of C1 and C2 domains of protein kinase $\mathrm{C}-\alpha$ in its membrane binding and activation. J. Biol. Chem. 274: 19852-19861.

Minami, H., Owada, Y., Suzuki, R., Handa, Y., and Kondo, H. 2000. Localization of mRNAs for novel, atypical as well as conventional protein kinase $\mathrm{C}$ (PKC) isoforms in the brain of developing and mature rats. J. Mol. Neurosci. 15: 121-135.

Mizuno, K., Saido, T.C., Ohno, S., Tamaoki, T., and Suzuki, K. 1993. Staurosporine-related compounds, K252a and UCN-01, inhibit both cPKC and nPKC. FEBS Lett. 330: 114-116.

Moroz, L.L., Edwards, J.R., Puthanveettil, S.V., Kohn, A.B., Ha, T., Heyland, A., Knudsen, B., Sahni, A., Yu, F., Liu, L., et al. 2006. Neuronal transcriptome of Aplysia: Neuronal compartments and circuitry. Cell 127: 1453-1467.

Moscat, J. and Diaz-Meco, M.T. 2000. The atypical protein kinase Cs. Functional specificity mediated by specific protein adapters. $E M B O$ Rep. 1: 399-403.

Nagy, G., Matti, U., Nehring, R.B., Binz, T., Rettig, J., Neher, E., and Sorensen, J.B. 2002. Protein kinase C-dependent phosphorylation of synaptosome-associated protein of $25 \mathrm{kDa}$ at Ser187 potentiates vesicle recruitment. J. Neurosci. 22: 9278-9286.

Naik, M.U., Benedikz, E., Hernandez, I., Libien, J., Hrabe, J., Valsamis, M., Dow-Edwards, D., Osman, M., and Sacktor, T.C. 2000. Distribution of protein kinase $\mathrm{M} \zeta$ and the complete protein kinase $\mathrm{C}$ isoform family in rat brain. J. Comp. Neurol. 426: 243-258.

Nakhost, A., Forscher, P., and Sossin, W.S. 1998. Binding of protein kinase C isoforms to actin in Aplysia. J. Neurochem. 71: 1221-1231.

Nakhost, A., Kabir, N., Forscher, P., and Sossin, W.S. 2002. Protein kinase $\mathrm{C}$ isoforms are translocated to microtubules in neurons. $J$. Biol. Chem. 277: 40633-40639.

Newton, A.C. 1995a. Protein kinase C. Seeing two domains. Curr. Biol. 5: $973-976$.

Newton, A.C. 1995b. Protein kinase C: Structure, function, and regulation. J. Biol. Chem. 270: 28495-28498.

Nilsson, J., Sengupta, J., Frank, J., and Nissen, P. 2004. Regulation of eukaryotic translation by the RACK1 protein: A platform for signalling molecules on the ribosome. EMBO Rep. 5: 1137-1141.

Nishikawa, K., Toker, A., Johannes, F.J., Songyang, Z., and Cantley, L.C. 1997. Determination of the specific substrate sequence motifs of protein kinase C isozymes. J. Biol. Chem. 272: 952-960.

Oancea, E. and Meyer, T. 1998. Protein kinase C as a molecular machine for decoding calcium and diacylglycerol signals. Cell 95: 307-318.

Ochoa, W.F., Garcia-Garcia, J., Fita, I., Corbalan-Garcia, S., Verdaguer, N., and Gomez-Fernandez, J.C. 2001. Structure of the C2 domain from novel protein kinase $\mathrm{C} \varepsilon$. A membrane binding model for $\mathrm{Ca}^{2+}$-independent C2 domains. J. Mol. Biol. 311: 837-849.

Ohno, S. 2001. Intercellular junctions and cellular polarity: The PAR-aPKC complex, a conserved core cassette playing fundamental roles in cell polarity. Curr. Opin. Cell Biol. 13: 641-648.

Olive, M.F., Mehmert, K.K., Nannini, M.A., Camarini, R., Messing, R.O. and Hodge, C.W. 2001. Reduced ethanol withdrawal severity and altered withdrawal-induced c-fos expression in various brain regions of mice lacking protein kinase C- $\varepsilon$. Neuroscience 103: 171-179.

Pappa, H., Murray-Rust, J., Dekker, L.V., Parker, P.J., and McDonald, N.Q. 1998. Crystal structure of the C2 domain from protein kinase C- $\delta$. Structure 6: 885-894.

Parekh, D., Ziegler, W., Yonezawa, K., Hara, K., and Parker, P.J. 1999. Mammalian TOR controls one of two kinase pathways acting upon nPKC $\delta$ and nPKCe. J. Biol. Chem. 274: 34758-34764.

Pastalkova, E., Serrano, P., Pinkhasova, D., Wallace, E., Fenton, A.A., and Sacktor, T.C. 2006. Storage of spatial information by the maintenance mechanism of LTP. Science 313: 1141-1144.

Pepio, A.M. and Sossin, W.S. 1998. The C2 domain of the $\mathrm{Ca}^{2+}$-independent protein kinase C Apl II inhibits phorbol ester binding to the $\mathrm{C} 1$ domain in a phosphatidic acid-sensitive manner. Biochemistry 37: 1256-1263.

Pepio, A.M. and Sossin, W.S. 2001. Membrane translocation of novel protein kinase Cs is regulated by phosphorylation of the $\mathrm{C} 2$ domain. J. Biol. Chem. 276: 3846-3855.

Pepio, A.M., Fan, X., and Sossin, W.S. 1998. The role of C2 domains in
$\mathrm{Ca}^{2+}$-activated and $\mathrm{Ca}^{2+}$-independent protein kinase Cs in Aplysia. J. Biol. Chem. 273: 19040-19048.

Pepio, A.M., Thibault, G.L., and Sossin, W.S. 2002.

Phosphoinositide-dependent kinase phosphorylation of protein kinase C Apl II Increases during intermediate facilitation in Aplysia. J. Biol. Chem. 277: 37116-37123.

Prekeris, R., Mayhew, M.W., Cooper, J.B., and Terrian, D.M. 1996. Identification and localization of an actin-binding motif that is unique to the $\varepsilon$ isoform of protein kinase $C$ and participates in the regulation of synaptic function. J. Cell Biol. 132: 77-90.

Raval, A.P., Dave, K.R., Mochly-Rosen, D., Sick, T.J., and Perez-Pinzon, M.A. 2003. $\varepsilon$ PKC is required for the induction of tolerance by ischemic and NMDA-mediated preconditioning in the organotypic hippocampal slice. J. Neurosci. 23: 384-391.

Ron, D., Luo, J., and Mochly-Rosen, D. 1995. C2 region-derived peptides inhibit translocation and function of $\beta$ protein kinase $C$ in vivo. $J$. Biol. Chem. 270: 24180-24187.

Rybin, V.O., Sabri, A., Short, J., Braz, J.C., Molkentin, J.D., and Steinberg, S.F. 2003. Cross-regulation of novel protein kinase C (PKC) isoform function in cardiomyocytes. Role of PKC epsilon in activation loop phosphorylations and PKC $\delta$ in hydrophobic motif phosphorylations. J. Biol. Chem. 278: 14555-14564.

Saito, N. 2003. Fluorescence imaging of protein kinase $C$ translocation in living cells. Methods Mol. Biol. 233: 93-103.

Saito, N. and Shirai, Y. 2002. Protein kinase C $\gamma($ PKC $\gamma)$ : Function of neuron specific isotype. J. Biochem. 132: 683-687.

Saitoh, N., Hori, T., and Takahashi, T. 2001. Activation of the $\varepsilon$ isoform of protein kinase $\mathrm{C}$ in the mammalian nerve terminal. Proc. Natl. Acad. Sci. 98: 14017-14021.

Sando, J.J. 2003. Complexities in protein kinase C activity assays: An introduction. Methods Mol. Biol. 233: 45-61.

Sarbassov, D.D., Ali, S.M., Kim, D.H., Guertin, D.A., Latek, R.R. Erdjument-Bromage, H., Tempst, P., and Sabatini, D.M. 2004. Rictor, a novel binding partner of mTOR, defines a rapamycin-insensitive and raptor-independent pathway that regulates the cytoskeleton. Curr. Biol. 14: 1296-1302.

Sawada, M., Cleary, L.J., and Byrne, J.H. 1989. Inositol trisphosphate and activators of protein kinase $\mathrm{C}$ modulate membrane currents in tail motor neurons of Aplysia. J. Neurophysiol. 61: 302-310.

Schechtman, D. and Mochly-Rosen, D. 2001. Adaptor proteins in protein kinase C-mediated signal transduction. Oncogene 20: 6339-6347.

Schechtman, D., Craske, M.L., Kheifets, V., Meyer, T., Schechtman, J., and Mochly-Rosen, D. 2004. A critical intramolecular interaction for protein kinase C $\varepsilon$ translocation. J. Biol. Chem. 279: 15831-15840.

Serrano, P., Yao, Y., and Sacktor, T.C. 2005. Persistent phosphorylation by protein kinase $\mathrm{M} \zeta$ maintains late-phase long-term potentiation. $J$. Neurosci. 25: 1979-1984.

Sieburth, D., Madison, J.M., and Kaplan, J.M. 2007. PKC-1 regulates secretion of neuropeptides. Nat. Neurosci. 10: 49-57.

Sivasankaran, R., Pei, J., Wang, K.C., Zhang, Y.P., Shields, C.B., Xu, X.M., and He, Z. 2004. PKC mediates inhibitory effects of myelin and chondroitin sulfate proteoglycans on axonal regeneration. Nat. Neurosci. 7: 261-268.

Slater, S.J., Milano, S.K., Stagliano, B.A., Gergich, K.J., Curry, J.P., Taddeo, F.J., and Stubbs, C.D. 2000. Interaction of protein kinase C with filamentous actin: Isozyme specificity resulting from divergent phorbol ester and calcium dependencies. Biochemistry 39: 271-280.

Slater, S.J., Seiz, J.L., Cook, A.C., Buzas, C.J., Malinowski, S.A., Kershner, J.L., Stagliano, B.A., and Stubbs, C.D. 2002. Regulation of PKC $\alpha$ activity by C1-C2 domain interactions. J. Biol. Chem. 277: 15277-15285.

Soh, J.W., Lee, E.H., Prywes, R., and Weinstein, I.B. 1999. Novel roles of specific isoforms of protein kinase $\mathrm{C}$ in activation of the c-fos serum response element. Mol. Cell. Biol. 19: 1313-1324.

Sossin, W.S. and Schwartz, J.H. 1992. Selective activation of $\mathrm{Ca}^{2+}$-activated PKCs in Aplysia neurons by 5-HT. J. Neurosci. 12: $1160-1168$.

Sossin, W.S., Diaz, A.R., and Schwartz, J.H. 1993. Characterization of two isoforms of protein kinase $\mathrm{C}$ in the nervous system of Aplysia californica. J. Biol. Chem. 268: 5763-5768.

Stahelin, R.V., Digman, M.A., Medkova, M., Ananthanarayanan, B. Melowic, H.R., Rafter, J.D., and Cho, W. 2005 Diacylglycerol-induced membrane targeting and activation of protein kinase $\mathrm{C} \varepsilon$ : Mechanistic differences between protein kinases

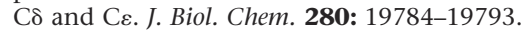

Staudinger, J., Lu, J., and Olson, E.N. 1997. Specific interaction of the PDZ domain protein PICK1 with the $\mathrm{COOH}$ terminus of protein kinase C- $\alpha$. J. Biol. Chem. 272: 32019-32024.

Stebbins, E.G. and Mochly-Rosen, D. 2001. Binding specificity for RACK1 resides in the V5 region of $\beta$ II protein kinase C. J. Biol. Chem. 276: 29644-29650. 
Sugita, S., Goldsmith, J.R., Baxter, D.A., and Byrne, J.H. 1992. Involvement of protein kinase $\mathrm{C}$ in serotonin-induced spike broadening and synaptic facilitation in sensorimotor connections of Aplysia. J. Neurophysiol. 68: 643-651.

Sugita, S., Baxter, D.A., and Byrne, J.H. 1994. Activators of protein kinase $\mathrm{C}$ mimic serotonin-induced modulation of a voltage-dependent potassium current in pleural sensory neurons of Aplysia. J. Neurophysiol. 72: 1240-1249.

Sutton, M.A. and Carew, T.J. 2000. Parallel molecular pathways mediate expression of distinct forms of intermediate-term facilitation at tail sensory-motor synapses in Aplysia. Neuron 26: 219-231.

Sutton, M.A., Bagnall, M.W., Sharma, S.K., Shobe, J., and Carew, T.J. 2004. Intermediate-term memory for site-specific sensitization in Aplysia is maintained by persistent activation of protein kinase C. J. Neurosci. 24: 3600-3609.

Tamaoki, T., Nomoto, H., Takahashi, I., Kato, Y., Morimoto, M., and Tomita, F. 1986. Staurosporine, a potent inhibitor of

phospholipid/Ca ${ }^{++}$dependent protein kinase. Biochem. Biophys. Res. Commun. 135: 397-402.

Terrian, D.M., Ways, D.K., and Gannon, R.L. 1991. A presynaptic role for protein kinase $\mathrm{C}$ in hippocampal mossy fiber synaptic transmission. Hippocampus 1: 303-314.

Toker, A. 2003. Genetic manipulation of protein kinase C in vivo. Methods Mol. Biol. 233: 475-489.

Torrecillas, A., Laynez, J., Menendez, M., Corbalan-Garcia, S., and Gomez-Fernandez, J.C. 2004. Calorimetric study of the interaction of the $\mathrm{C} 2$ domains of classical protein kinase $\mathrm{C}$ isoenzymes with $\mathrm{Ca}^{2+}$ and phospholipids. Biochemistry 43: 11727-11739.

Toullec, D., Pianetti, P., Coste, H., Bellevergue, P., Grand-Perret, T., Ajakane, M., Baudet, V., Boissin, P., Boursier, E., Loriolle, F., et al. 1991. The bisindolylmaleimide GF $109203 \mathrm{X}$ is a potent and selective inhibitor of protein kinase C. J. Biol. Chem. 266: 15771-15781.

Tu, J.C., Xiao, B., Yuan, J.P., Lanahan, A.A., Leoffert, K., Li, M., Linden,
D.J., and Worley, P.F. 1998. Homer binds a novel proline-rich motif and links group 1 metabotropic glutamate receptors with IP3 receptors. Neuron 21: 717-726.

Wan, Q., Negroiu, N., and Abrams, T.W. 2006. PKC detection of firing patterns at Aplysia sensory neuron synapses may be mediated by kinetics of PKC-membrane binding. Soc. Neurosci. Abstracts 813.821.

Ways, D.K., Cook, P.P., Webster, C., and Parker, P.J. 1992. Effect of

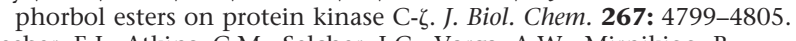

Weeber, E.J., Atkins, C.M., Selcher, J.C., Varga, A.W., Mirnikjoo, B., Paylor, R., Leitges, M., and Sweatt, J.D. 2000. A role for the $\beta$ isoform of protein kinase $\mathrm{C}$ in fear conditioning. J. Neurosci. 20: $5906-5914$.

Yanow, S.K., Manceau, F., Hislop, J., Castellucci, V.F., and Sossin, W.S. 1998. The biochemical pathways by which serotonin regulates translation in the nervous system of Aplysia. J. Neurochem. 70: $572-583$.

Zabouri, N. and Sossin, W.S. 2002. Oxidation induces autonomous activation of protein kinase C Apl I, but not protein kinase C Apl II in homogenates of Aplysia neurons. Neurosci. Lett. 329: 257-260.

Zhao, Y., Leal, K., Abi-Farah, C., Martin, K.C., Sossin, W.S., and Klein, M. 2006. Isoform specificity of PKC translocation in living Aplysia sensory neurons and a role for $\mathrm{Ca}^{2+}$-dependent PKC APL I in the induction of intermediate-term facilitation. J. Neurosci. 26: 8847-8856.

Zhou, Y., Li, G.D., and Zhao, Z.Q. 2003. State-dependent phosphorylation of $\varepsilon$-isozyme of protein kinase $C$ in adult rat dorsal root ganglia after inflammation and nerve injury. J. Neurochem. 85: $571-580$.

Received November 13, 2006; accepted in revised form February 7, 2007.

\section{Learning \& Memory}

www.learnmem.org 


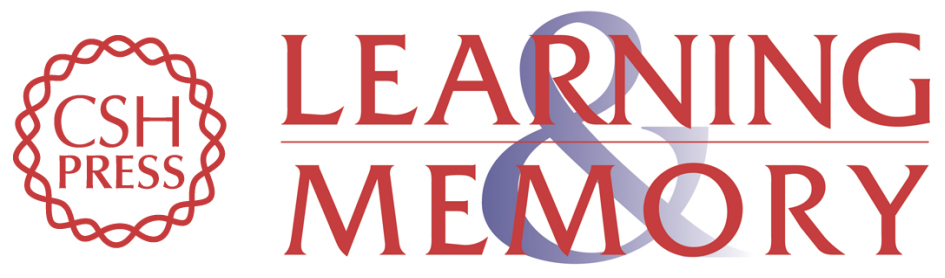

\section{Isoform specificity of protein kinase Cs in synaptic plasticity}

Wayne S. Sossin

Learn. Mem. 2007, 14:

Access the most recent version at doi:10.1101//m.469707

References This article cites 144 articles, 80 of which can be accessed free at: http://learnmem.cshlp.org/content/14/4/236.full.html\#ref-list-1

License

Email Alerting Receive free email alerts when new articles cite this article - sign up in the box at the Service top right corner of the article or click here. 